\title{
O ENSINO DE RELEVO NO SIMPÓSIO BRASILEIRO DE GEOGRAFIA FÍSICA APLICADA (SBGFA)
}

\author{
Gean Santos de Novais ${ }^{(a)}$, Samuel Oliveira Mendes ${ }^{(\mathrm{b})}$, Eliana marta Barbosa de Morais ${ }^{(\mathrm{c})}$ \\ (a) Mestrando do Programa de pós-Graduação em Geografia - PPGeo, no Instituto de Estudos Socioambientais - \\ IESA, da Universidade Federal de Goiás - UFG, denovaisgean@gmail.com \\ (b) Mestrando do Programa de pós-Graduação em Geografia - PPGeo, no Instituto de Estudos Socioambientais - \\ IESA, da Universidade Federal de Goiás - UFG, samuel_ufg@ hotmail.com \\ (c) Professora Dra. do curso de Geografia do Instituto de Estudos Socioambientais - IESA, da Universidade \\ Federal de Goiás - UFG, elianamarta.ufg@gmail.com
}

\section{Eixo: GEOGRAFIA FÍSICA: CURRÍCULO, FORMAÇÃO E PRÁTICAS DE ENSINO}

\begin{abstract}
Resumo
A finalidade deste trabalho foi discutir a maneira como tem sido abordado o ensino do relevo em artigos publicados no Simpósio Brasileiro de Geografia Física Aplicada (SBGFA), nas edições ocorridas de 2005 a 2015. Visando alcançar este objetivo, realizamos a revisão bibliográfica acerca do tema; identificamos os anais do referido evento no período mencionado; e selecionamos os trabalhos sobre o relevo nos eixos de ensino. Os resultados indicaram que uma parcela expressiva dos trabalhos apresentam proposições para o ensino do relevo na Geografia Escolar. Além disso, constatamos que, para esse nível de ensino, o cerne das publicações está no "como ensinar", em contrapartida, as pesquisas que apresentam sugestões de abordagem desse componente físico-natural no Ensino superior, o foco é o "o que ensinar".
\end{abstract}

Palavras Chave: Relevo. Ensino de Geografia. SBGFA.

\section{Introdução}

O relevo é um importante componente físico-natural do espaço geográfico, sendo, por vezes um conteúdo recorrentemente trabalhado no Ensino de Geografia. Assim, pensamos que, investigar o seu ensino é relevante, para que possamos entender o que, e como tem sido proposto o trabalho com esse conteúdo. Para isso, uma das possibilidades é debruçar-se sobre as pesquisas publicadas em eventos científicos, com vistas à discutir as proposições acerca do ensino de relevo, e as possíveis contribuições delas para o Ensino de Geografia.

A sociedade não está simplesmente assentada sobre o relevo e suas formas, pois, nesse processo de uso e ocupação, são promovidas inúmeras e constantes transformações, seja ao construir moradias, estradas, barragens, seja ao desenvolver atividades agrícolas, de mineração, entre outras. Tudo isso implica em ações e modificações no relevo, em que a sociedade vai criando condições para a sua existência. Nesse contexto, compreender o relevo e suas dinâmicas é fundamental para identificar potencialidades e limitações para o uso e ocupação humana, em especial, no que se circunscreve à problemática dos riscos, os quais uma parcela da população está vulnerável. 
XVII Simpósio Brasileiro de Geografia Fisica Aplicada

I Congresso Nacional

de Geografia Física

\section{OS DESAFIOS DA GEOGRAFIA FÍSICA NA FRONTEIRA DO CONHECIMENTO \\ Instituto de Geociências - Unicamp \\ Campinas - SP \\ 28 de Junho à 02 de Julho de 2017}

Diante disso, estabelecemos como objetivos, deste trabalho, discutir a maneira como tem sido abordado o ensino do relevo em artigos publicados no Simpósio Brasileiro de Geografia Física Aplicada (SBGFA), nas edições ocorridas de 2005 a $2015^{1}$. Para tanto, selecionamos e analisamos os textos pertencentes ao eixo de ensino deste evento, por considerá-lo significativo no âmbito da Geografia. Almejamos com isso, entender quais questões tem fomentado os debates acerca do ensino de relevo, em especial, no contexto da Educação Básica.

Para compor o corpo desta pesquisa, consideramos apenas os trabalhos completos publicados. A seleção foi feita tendo como referência os termos: relevo; geomorfologia; morfometria e geologia, as análises foram desenvolvidas com base na leitura dos títulos, dos resumos e das palavras-chave. Na a ausência de alguma dessas informações, realizamos a leitura integral das publicações.

\section{Resultados e discussão}

Para iniciar a discussão, apresentamos a seguir os números gerais do levantamento dos trabalhos publicados no eixo de ensino do SBGFA, dos quais é possível obter uma compreensão inicial do universo pesquisado (Tabela I).

Tabela I - Edições do SBGFA pesquisadas, 2005* - 2015.

\begin{tabular}{c|c|c|c|c|c}
\hline \hline Ano & $\begin{array}{c}\mathbf{N}^{\mathbf{0}} \text { de trabalhos } \\
\text { Publicados no } \\
\text { Evento }\end{array}$ & $\begin{array}{c}\mathbf{N}^{\mathbf{0}} \text { de trabalhos } \\
\text { no Eixo de } \\
\text { Ensino }\end{array}$ & $\begin{array}{c}\mathbf{N}^{\mathbf{0}} \text { de trabalhos } \\
\text { sobre Ensino de } \\
\text { Relevo }\end{array}$ & $\begin{array}{c}\mathbf{N}^{\mathbf{0}} \text { de trab. sobre } \\
\text { Relevo com foco } \\
\text { na Educ. Básica }\end{array}$ & $\begin{array}{c}\mathbf{N}^{\mathbf{0}} \text { de trab. sobre } \\
\text { Relevo com foco } \\
\text { no Ens. Superior }\end{array}$ \\
\hline \hline 2005 & - & - & - & - & - \\
\hline 2007 & 538 & 32 & 5 & 3 & 2 \\
\hline 2009 & 553 & 38 & 4 & 3 & 1 \\
\hline 2011 & 722 & 44 & 2 & 3 & 1 \\
\hline 2013 & 633 & 44 & 3 & 5 & 0 \\
\hline 2015 & 632 & 46 & 7 & $\mathbf{1 5}$ & 2 \\
\hline Total & $\mathbf{3 0 7 8}$ & $\mathbf{2 0 4}$ & $\mathbf{2 1}$ & $\mathbf{6}$ \\
\hline \hline
\end{tabular}

Fonte. SBGFA (Organizado por NOVAIS; MENDES, 2017, grifo dos autores).

Conforme evidenciado na tabela, contabilizamos um total de 3078 trabalhos no SBGFA, no período analisado. Deste total, 204 (6,6\%) trabalhos pertencem ao eixo de ensino, dentre eles, 21 textos $(10,2$ $\%)$ versam sobre ensino do relevo, os quais estão presentes em todas as edições do evento (Quadro I). Entretanto, os números demonstram, também, que não há uma regularidade relativa à quantidade de

\footnotetext{
${ }^{1}$ Para o recorte temporal deste trabalho (de 10 anos) consideramos a ininterrupta periodicidade do evento; as dificuldades para acessar os anais de edições ocorridas anteriormente a esse período; e por entender que esse recorte é satisfatório para compreendermos as reflexões acerca da temática investigada.

* Até o presente momento, ainda não tivemos acesso aos anais do SBGFA/2005. A única informação que encontramos dessa edição foi um sumário da Revista do Departamento de Geografia da Universidade de São Paulo - USP, contendo somente os títulos de 12 textos publicados no $16^{\circ}$ volume da revista. Nesse sentido, por não termos conseguido acessar a totalidade dos anais, analisamos os textos publicados a partir da XII edição, 2007.
} 


\section{OS DESAFIOS DA GEOGRAFIA FÍSICA NA FRONTEIRA DO CONHECIMENTO \\ Instituto de Geociências - Unicamp \\ Campinas - SP \\ 28 de Junho à 02 de Julho de 2017}

trabalhos publicados sobre ensino de relevo, e que essa temática, no contexto do evento e do eixo de ensino, não assume papel central.

\begin{tabular}{|c|c|}
\hline Ano & Título do trabalho \\
\hline \multirow{5}{*}{2007} & As bases teóricas e conceituais do ensino de Geomorfologia \\
\hline & $\begin{array}{l}\text { Elaboração de maquete do relevo associada aos tipos de solos predominantes na cidade de } \\
\text { Presidente Prudente - SP }\end{array}$ \\
\hline & $\begin{array}{l}\text { Elaboração e difusão de um dicionário visual de Geomorfologia nas escolas da rede pública } \\
\text { de ensino em Santa Maria - RS }\end{array}$ \\
\hline & O uso de modelos dinâmicos no ensino da disciplina de Geomorfologia \\
\hline & $\begin{array}{l}\text { Proposta para o estudo de relevo cárstico no ensino médio do estado de São Paulo na } \\
\text { disciplina de geografia }\end{array}$ \\
\hline \multirow{4}{*}{2009} & $\begin{array}{l}\text { A Geografia Física nas aulas de Geografia nos quatro últimos anos do ensino fundamental: a } \\
\text { importância dos conteúdos de Geomorfologia na formação do aluno }\end{array}$ \\
\hline & A utilização de mapas turísticos para ensino da Geomorfologia em sala de aula \\
\hline & Abordagens do relevo e suas dinâmicas em livros didáticos de geografia \\
\hline & $\begin{array}{l}\text { Geomorfologia fluvial, formação de professores e prática docente: reflexões sobre o Rio } \\
\text { Imboaçu - São Gonçalo - RJ }\end{array}$ \\
\hline \multirow{2}{*}{2011} & $\begin{array}{l}\text { A utilização de modelos digitais de elevação (MDEs) como material auxiliar no ensino de } \\
\text { Geomorfologia }\end{array}$ \\
\hline & $\begin{array}{l}\text { Integração universidade-escola: adequação do laboratório de Geologia, Geomorfologia e } \\
\text { recursos hídricos aos conteúdos curriculares do ensino fundamental e médio de geografia }\end{array}$ \\
\hline \multirow{3}{*}{2013} & A construção do conceito de níveis hipsométricos - ensino de geografia física \\
\hline & O relevo e a Cidade de Goiânia na Geografia Escolar \\
\hline & $\begin{array}{l}\text { Recurso Didático Auxiliar da Identificação dos Tipos de Leitos Fluviais: Uma Contribuição } \\
\text { ao Ensino de Geomorfologia no Colégio Marista Santa Maria, Santa Maria/RS }\end{array}$ \\
\hline \multirow{7}{*}{2015} & A Geomorfológica brasileira nas década de $30,40,50$ e 60 do século $\mathrm{xx}$ \\
\hline & Análise da Geomorfologia do distrito de Taperuaba aplicada ao ensino de geografia \\
\hline & Caracterização Geomorfológica na bacia do alto paraguai a partir de perfis transversais \\
\hline & Ensinar a geografia física por meio de oficina de modelagem de relevo \\
\hline & $\begin{array}{l}\text { O ensino de geografia na escola básica: uma análise da utilização das imagens de satélite no } \\
\text { contexto da abordagem geomorfológica }\end{array}$ \\
\hline & $\begin{array}{l}\text { O uso de recursos didáticos para o ensino de Geomorfologia e Geologia no ensino básico: } \\
\text { maquete das unidades geomorfológicas do rio grande do sul }\end{array}$ \\
\hline & $\begin{array}{l}\text { Trabalho com maquetes em sala de aula como metodologia de representação do relevo no } \\
\text { ensino da geografia }\end{array}$ \\
\hline
\end{tabular}

Quadro 1. Trabalhos publicados sobre ensino de relevo no SBGFA, 2005 - 2015.

Fonte. SBGFA (Organizado por NOVAIS; MENDES, 2017, grifo dos autores).

No $12^{\circ}$ SBGFA, que ocorreu em 2007 na cidade de Natal - RN, encontramos no eixo intitulado "Pesquisa e Ensino da Geografia Física com ênfase social e ambiental" cinco trabalhos.

A primeira publicação buscou analisar as correntes do pensamento da geomorfologia AngloAmericana e Alemã e as suas influências nos programas de ensino das universidades públicas do Estado de São Paulo (USP e UNESP, campi de Rio Claro e Presidente Prudente). Como resultados, os 
autores concluíram que no Instituto de Geociências e Ciências Exatas da Universidade Estadual Paulista de Rio Claro-SP as pesquisas apontam para a perspectiva alemã, de cunho quantitativista, tendo como maior representante Antônio Christofoletti. Enquanto que, no Instituto de Geografia da Universidade de São Paulo as pesquisas desenvolvidas estão ligadas à escola germânica, cujo expoente maior é o pesquisador Aziz Nacib Ab’Saber.

O segundo trabalho teve como objetivo elaborar uma maquete do relevo associado aos tipos de solos predominantes da cidade de Presidente Prudente (SP), buscando a visualização tridimensional do modelado do referido município. Como resultados, os autores apontaram contribuições para o ensino de Geografia Física (tanto no Ensino Fundamental quanto no Ensino Médio), especificamente com os conhecimentos geomorfológicos, que, por vezes, são tratados de modo fragmentado e deslocados da realidade.

Em relação a fragmentação na abordagem de relevo, Roque Ascenção (2009) e Morais (2011) tem chamado a atenção sobre a pouca ou inexistente relação estabelecida por professores de Geografia ao ensinarem o conteúdo relevo, bem como a sua dissociação em relação a outros conteúdos a exemplo de clima, solos, rochas, entre outros componentes. Em suma, não há uma abordagem integrada, o que pode dificultar a compreensão do aluno a respeito do espaço em que vivencia, da dinâmica e da complexidade que compõe esse espaço geográfico.

No terceiro trabalho os objetivos propostos foram: planejar, produzir e difundir, junto às escolas da rede pública de ensino de Santa Maria - RS, um dicionário visual de geomorfologia, em formato digital, que servisse como suporte teórico e como instrumento didático para a disciplina de Geografia. A elaboração do dicionário, segundo os autores, mostrou-se importante por, não apenas oferecer mais uma opção didática ao professor, mas por buscar favorecer a relação entre a universidade e a rede pública de ensino, além de contribuir com o ensino de conteúdos de Geomorfologia.

O quarto trabalho objetivou reproduzir sistemas morfológicos e processos morfodinâmicos a partir da elaboração de modelos dinâmicos. Os autores indicaram a intenção de contribuir para a melhoria do ensino de Geomorfologia, permitindo um estudo mais participativo e interessante para os alunos de graduação, de modo a propor a utilização de outros métodos no ensino desta disciplina para além dos tradicionais livros. Os autores indicam que tanto modelos fixos (maquetes), como modelos dinâmicos, tornam-se uma ferramenta de grande importância, interagindo o graduando e a disciplina oferecida.

O quinto trabalho pautou-se em estudar o relevo cárstico no Ensino Médio do Estado de São Paulo, na disciplina de Geografia, buscando aprimorar os conhecimentos sobre o ciclo hidrológico, a esculturação de rochas e a dinâmica externa da Terra. Como contribuições, a autora apresentou os dados da pesquisa que demonstram maior conhecimento a respeito do ciclo hidrológico e sua função 
na dinâmica externa terrestre, principalmente na esculturação do relevo cárstico, que possui grande relevância no Ensino de Geografia.

É importante expor aqui algumas considerações sobre a abordagem do relevo em livros didáticos de Geografia que também foram apontadas no quarto trabalho desta $12^{\mathrm{a}}$ edição/2007 do SBGFA. Morais (2014) ao investigar as temáticas físico-naturais (relevo, rochas e solos) na Geografia Escolar, identificou que os professores de Geografia recorrem, principalmente, ao livro didático para encaminhar o ensino desses conteúdos. Bertolini e Valadão (2009) verificaram ainda que, por vezes, a abordagem do conteúdo relevo, nesses materiais pedagógico-didáticos, exploram apenas as macroformas (Planícies, Planaltos, Bacias sedimentares), formas estas que remetem a escalas de tempo e espaço distantes das vivenciadas pelos alunos.

No $13^{\circ}$ SBGFA, que ocorreu em 2009 na cidade de Viçosa - MG, foram identificados no eixo "Geografia Física e Ensino" quatro trabalhos, que dialogam com o relevo e o seu ensino.

O primeiro texto teve como objetivo analisar os conteúdos de Geomorfologia em livros didáticos de Geografia da $6^{\mathrm{a}}, 7^{\mathrm{a}}$ e $8^{\mathrm{a}}$ séries (ou $7^{\circ}, 8^{\circ}$ e $9^{\circ}$ anos) de seis coleções utilizadas na rede pública de ensino. Os autores verificaram que, ao buscar estabelecer uma relação entre os conteúdos e a vida cotidiana, o principal apoio dos livros didáticos são materiais visuais.

O objetivo do segundo trabalho foi demonstrar a utilidade dos mapas turísticos como ferramentas para o Ensino da Geografia, bem como para compreensão dos conceitos geomorfológicos. Como resultados, os autores apontaram potencialidades dos mapas turísticos, combinados com o estudo da Geomorfologia Costeira, para que o aluno possa valorizar estética, cultural, afetiva e economicamente as diferentes formas de relevo.

O terceiro trabalho debruçou-se sobre as bases epistemológicas, metodológicas e pedagógicas que fundamentam o conteúdo relevo nos livros didáticos dos anos finais do Ensino Fundamental. Como resultados, os autores constataram a permanência de uma base teórico-metodológica que distancia as dinâmicas do relevo e o cotidiano imediato dos alunos.

O objetivo do quarto trabalho foi desenvolver uma proposta pedagógica com graduandos, a partir do estudo das bacias de drenagem do Rio Imboaçu, São Gonçalo - RJ. Os autores indicaram como resultado a mobilização dos graduandos para compreensão acerca da importância da questão fluvial e dos impactos para as comunidades em que ali habitam, além da preservação dos rios.

No $14^{\circ}$ SBGFA, que ocorreu em 2011 na cidade de Dourados - MS, encontramos dois textos sobre o ensino de relevo. Um no eixo denominado "Espaços de construção de conhecimentos" e outro no eixo intitulado "Espaços de diálogos e práticas". 
O primeiro trabalho objetivou discutir a utilização de Modelos Digitais de Elevação (MDEs) no ensino de Geomorfologia por meio da elaboração de animações e imagens tridimensionais que auxiliem os alunos na interpretação de diferentes feições do relevo. Os autores indicaram que, ao testar a aplicabilidade de MDEs, que poderá constituir-se em uma ferramenta com grande potencial na realização de futuros mapeamentos geomorfológico, foi possível visualizar tridimensionalmente as diferentes feições do relevo durante a elaboração dos mapas. Com isso, pode-se auxiliar o ensino de diferentes conteúdos da geomorfologia.

O objetivo do segundo trabalho foi integrar conteúdos geográficos do campo da geologia, geomorfologia e recursos hídricos, oferecidos nas escolas da rede pública de Presidente Prudente - SP, a partir do projeto de extensão desenvolvido na FCT/UNESP, campus localizado na mesma cidade. Segundo os autores, os resultados obtidos a partir da adequação do laboratório possibilitaram o treinamento didático dos bolsistas, contribuindo para a formação inicial dos mesmos. Além disso, observou-se que a comunidade escolar do ensino fundamental e médio da rede pública, envolvida no projeto, passou a frequentar e usufruir das apresentações dos materiais didáticos e sua explicação em relação a temas ambientais.

O $15^{\circ}$ SBGFA ocorreu em 2013 na cidade de Vitória - ES. Nessa edição encontramos no eixo "Ensinando Geografia Física", três textos que abordam algum aspecto do relevo e seu ensino.

O primeiro trabalho teve como objetivo incentivar a execução de atividades em sala de aula relacionadas à Geografia Física a partir da proposição de uma atividade didática que consiste na montagem de maquete visando construir o conceito de níveis hipsométricos. Os autores indicaram que a atividade mostrou-se como um importante instrumento para a difusão da Geografia Física na escola, auxiliando na construção de conhecimentos relativos ao conceito de hipsometria, bem como para o entendimento da formação e direcionamento das bacias hidrográficas, de acordo com o relevo local.

O segundo trabalho teve como preocupação central questionar o ensino de relevo na Educação Básica. Como resultados as autoras destacaram que os professores de Geografia possuem dificuldades para encaminhar o ensino desse conteúdo, em especial, quando o foco é a cidade onde eles e seus alunos residem. Como uma das possíveis causas para essa problemática as autoras indicaram a escassez de bibliografias que tratam sobre o relevo de Goiânia - GO.

No terceiro trabalho o objetivo foi elaborar um recurso didático capaz de auxiliar no processo de ensino dos diferentes tipos de leitos fluviais e validá-lo com alunos do sexto ano. Como resultados, os autores destacaram que os alunos compreenderam a inter-relação rio/relevo, bem como todo o arranjo de ações referentes aos mesmos, seja a drenagem da água que escoa sobre o relevo, assim como o transporte de materiais intemperizados dos pontos mais altos aos mais baixos, devido à ação da gravidade, e por qual motivo ocorre o aumento do nível dos leitos fluviais. 
A partir do conjunto de trabalhos, por hora analisados, podemos pontuar que há dificuldades em relação ao ensino do conteúdo relevo, como já verificado por outras pesquisas - Morais (2011, 2013 e 2014) e Roque Ascenção (2009, 2013a e 2013b) - principalmente ao estabelecer uma relação entre este conteúdo e o contexto em que a escola ou o aluno está inserido, situando os problemas que acontecem no bairro ou na comunidade, por exemplo. Diante disso, o professor deve exercer um papel fundamental, o de incitar a formulação de hipóteses, por parte dos alunos, visando contribuir para a formação de um raciocínio coerente, que efetivamente explique os problemas inerentes à sua realidade (ROQUE ASCENÇÃO; VALADÃO, 2013).

O $16^{\circ}$ SBGFA foi realizado em 2015 na cidade de Teresina - PI. Nele identificamos sete trabalhos no eixo "Geografia Física - Ensino, pesquisa e extensão" acerca do ensino de relevo.

A primeira publicação objetivou entender qual a relação entre a sistematização da disciplina de Geomorfologia no Brasil, assim como sua ligação com o contexto político e econômico vigente no País a partir das décadas de 30, 40, 50 e 60 do século XX. Os autores verificaram que o desenvolvimento científico e tecnológico de ambas as escolas geomorfológicas (Americana e Germânica) são dependentes de sua aplicação no campo político eminentemente econômico das nações que as utilizam. Eles pontuam ainda que, os primeiros trabalhos aqui realizados são baseados em uma ciência geográfica que adota um método descritivo ligado aos institutos histórico-geográficos, a nível nacional e estadual, e à Sociedade Brasileira de Geografia.

No segundo trabalho o objetivo foi contribuir com as reflexões sobre a geomorfologia do distrito de Taperuaba - CE, a partir de uma visão didática. Os autores elencaram como resultados alcançados a identificação de compartimentações geomorfológicas na área de estudo, sendo que tal fato apresentase como potencialidade para o processo educativo, tendo a paisagem como elemento norteador da categoria analítica da dinâmica ambiental concebida sobre processos pedagógicos do estudo do relevo. Em relação aos livros didáticos, observou-se que estes materiais não apresentam elementos norteadores para o processo de ensino e aprendizagem que possibilite o ensino dinâmico da ciência geográfica, ressaltando as compartimentações geomorfológicas.

A finalidade do terceiro trabalho foi caracterizar, a partir de perfis transversais, o controle estrutural da bacia do Alto Paraguai - Pantanal Superior. Os autores identificaram na Serra do Poção fraturas consequentes do processo de dobramento. Na serra do Tarumã, verificou-se que esta se apresenta fortemente arrasada, com um relevo bem marcado pela drenagem. Na Planície do rio Paraguai, a drenagem mostra-se complexa apresentando diversas formas peculiares como bacias, lagoas e vazantes, bem como diversas feições testemunhos dos processos evolutivos.

O quarto trabalho buscou discutir a importância da oficina de modelagem de relevo nas turmas de $6^{\circ}$ ano no CIEP - Luís Caçador - São Gonçalo - RJ. Como resultados, os autores indicaram que com o 
desenvolvimento das oficinas, perceberam as interações que os alunos estabelecem ao realizarem as modelagens, ao entenderem como pode ser uma forma de relevo, e ao conceituá-la, bem como a partir do dialogo com outros estudantes e professores.

O quinto trabalho discute a construção do conhecimento geográfico, com enfoque na abordagem sobre a Geomorfologia, a partir da análise do emprego de imagens de satélites como recurso didático. Como resultados, os autores indicaram a importância da utilização das imagens de sensoriamento como recurso didático no ensino de Geomorfologia. Contudo, ressaltam que há a necessidade de uma exploração mais intensa desse recurso nos estudos geográficos, para que possam contribuir com a representação e construção do conhecimento socioespacial.

O sexto trabalho propôs construir uma maquete das unidades geomorfológicas do Rio Grande do Sul para discutir conteúdos da Geografia Física no ensino básico, como rochas, minerais, cartografia, relevo, entre outros. Os autores ressaltaram que, a partir das experiências com os alunos nas discussões e na prática com a maquete, os conteúdos foram construídos de forma ativa, permitindo que os estudantes conhecessem aspectos do lugar em que vivem, assim como a evolução e a formação das unidades geomorfológicas do Rio Grande do Sul.

O objetivo pautado no sétimo trabalho foi contribuir para o estudo do relevo a partir da elaboração de maquetes para representar as informações visuais do espaço e suas dinâmicas geomorfológicas em diferentes escalas. Segundo os autores, foi possível abordar uma gama de conteúdos para estudar o relevo, além de incentivar a criatividade, reflexão e o trabalho coletivo dos alunos, ampliando assim as suas noções espaciais.

É possível perceber que os trabalhos têm apontado para diferentes proposições, sejam para aprimorar conhecimentos, seja realizar oficinas e elaborar materiais didáticos. Entretanto, consideramos importante questionar, qual o papel do professor nessas propostas? Que abordagem os docentes poderiam desenvolver para que essas estratégias de ensino contribuam efetivamente para o processo de ensino e aprendizagem de Geografia, em especial, no que se circunscreve à abordagem do relevo? A partir desses questionamentos, colocados ao longo do texto, exploramos com mais ênfase, alguns pontos. A seguir apresentamos as principais constatações.

No conjunto dos textos identificados e analisados, foi possível observar, de forma mais evidente, a proporcionalidade relativa aos trabalhos sobre ensino de relevo, em relação a quantidade de trabalhos publicados no eixo de ensino. Além disso, acrescentamos a informação que diz respeito ao foco de investigação e direcionamento das proposições desses trabalhos em relação aos diferentes níveis de ensino (Figura 1). 


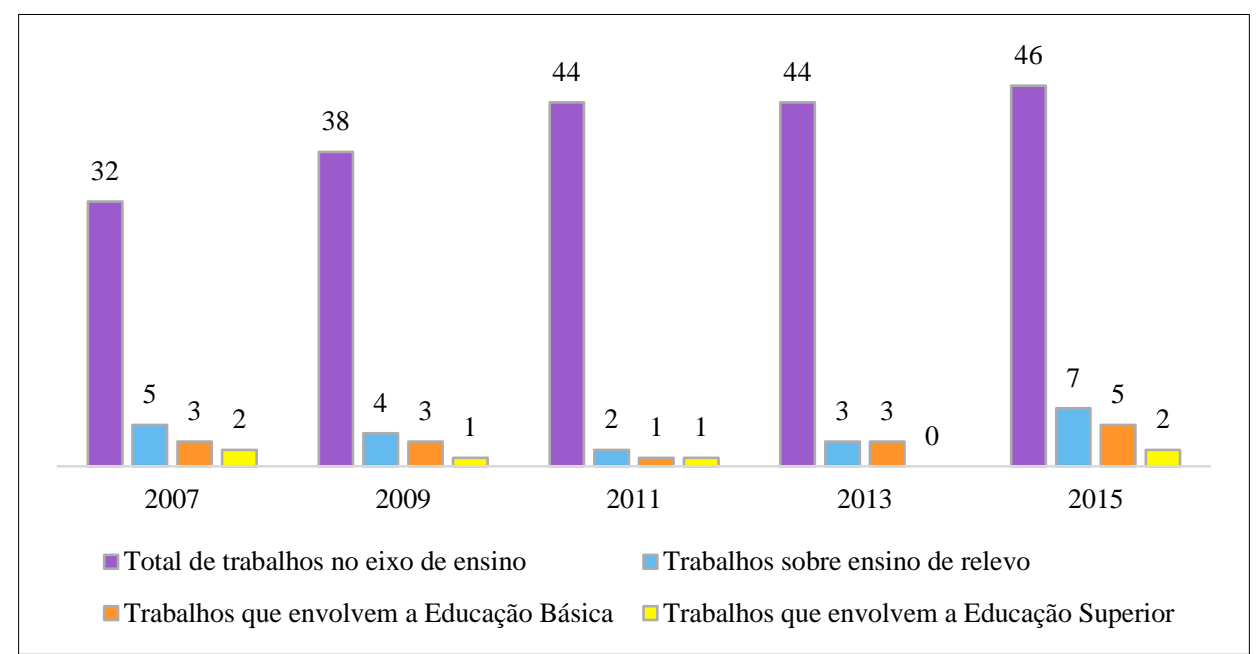

Figura 1 - Quantidade e foco dos trabalhos sobre ensino de relevo no SBGFA, 2005 - 2015.

Conforme exposto na figura, é possível verificar que a maior parcela dos trabalhos sobre ensino de relevo tem como foco de investigação ou de direcionamento de suas proposições a Educação Básica, 15 trabalhos $(71,4 \%)$. Já no caso das pesquisas que investigam ou fazem proposições direcionadas ao Ensino Superior, identificamos 6 trabalhos $(28,5 \%)$.

Verificamos ainda que na XV edição/2013 não houve nenhum trabalho envolvendo o Ensino Superior. Em contrapartida, os trabalhos que envolvem ou fazem proposições para a Educação Básica se fizeram presentes em todas as edições do SBGFA investigadas. Deste modo, os dados coletados no período 10 anos - nos permitem afirmar que há uma predominância de trabalhos sobre o ensino do relevo direcionados à Educação Básica.

Outro dado importante que verificamos, diz respeito às principais sugestões que os trabalhos analisados se propõem a desenvolver (Figura 2).

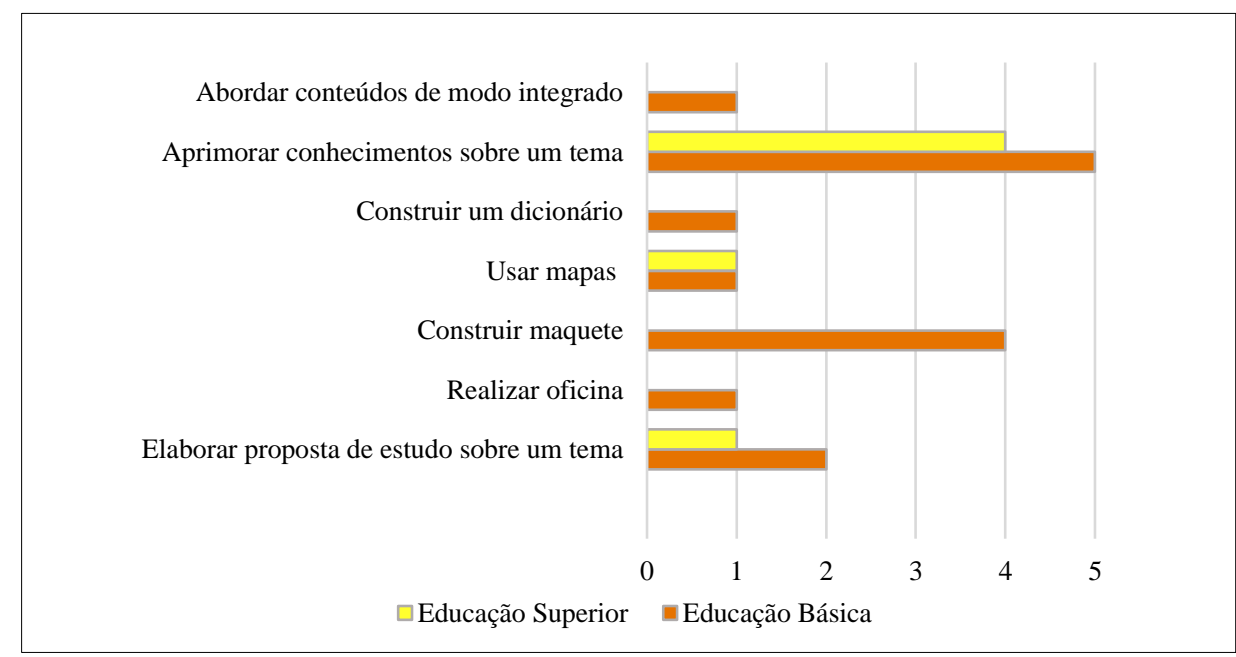

Figura 2 - Proposições feitas pelos trabalhos analisados sobre ensino de relevo no SBGFA, 2005-2015 
Em relação ao Ensino Superior, prevalece a finalidade de "Aprimorar conhecimentos sobre um tema/conteúdo" As propostas voltadas para este nível de ensino envolvem questões de investigação teórica. Como exemplo, citamos a investigação das correntes que influenciaram a Geomorfologia brasileira. Outras sugestões desenvolvidas nos trabalhos, para este nível de ensino, foram "Elaborar propostas de estudo sobre um tema" e impulsionar o uso de mapas nas aulas de Geografia.

No caso da Educação Básica, destacam-se "Aprimorar conhecimentos sobre um tema/conteúdo", do mesmo modo que propor a confecção de "Maquetes" e "Elaborar propostas de estudos sobre um tema". Para esse nível de ensino, é possível notar que as propostas são mais diversificadas que aquelas voltadas ao Ensino Superior. Algumas envolvem procedimentos de cunho mais prático no seu desenvolvimento, como a confecção de materiais, a exemplo de maquetes.

Os trabalhos publicados nos eixos de ensino do SBGFA reforçam algumas questões já mencionadas ao longo deste texto, como as sobre o livro didático de Geografia. Além disso, observamos que as pesquisas apresentadas, não só nas edições desse evento, ocorridas no recorte temporal estabelecido, tem proposto a utilização de outros recursos como mapas turísticos e maquetes para trabalhar com conteúdos da Geomorfologia e de outras áreas da Geografia Física. No entanto, pouco tem se discutido o papel do professor como mediador do processo de ensino e aprendizagem no trabalho com os conteúdos dessas áreas e com as sugestões de metodologias para o seu ensino.

Acerca desta problemática, corroboramos Schulman $(2004 ; 2005)$ ao ressaltar que, para a constituição de um bom professor, o domínio do conteúdo, somente, não é o bastante. Possuir apenas os conhecimentos didáticos também não é suficiente. Para esse autor, o trabalho do professor deve referenciar-se no "Conhecimento Didático do Conteúdo", que não é a somatória, mas a articulação entre conteúdo e didática.

Outro ponto importante que destacamos, principalmente sobre o ensino do relevo é que, mesmo a maioria das pesquisas apontando dificuldades para o trabalho com este conteúdo, apenas dois textos fazem uma discussão acerca da escala utilizada para estudá-lo. Além disso, somente um trabalho estabeleceu uma relação dessa dificuldade, a de tratar esse conteúdo em uma escala que seja mais próxima daquela vivenciada pelos alunos. Esse fato pode contribuir para que esses sujeitos se sintam desinteressados ao estudar relevo. Soma-se, ainda, a falta de bibliografias que caminhem nessa direção. $\mathrm{O}$ que pode ser considerado um entrave para o trabalho docente acerca do ensino desse conteúdo.

\section{Considerações finais}

Ficou evidenciado nos trabalhos, de um modo geral, que a forma como o conteúdo relevo vem sendo tratado, principalmente nos livros didáticos de Geografia - prezando por uma abordagem macroescalar 
- não tem favorecido o entendimento desse componente físico-natural como um elemento dinâmico, que compõe o espaço geográfico, e que tem ficado alheio, essencialmente no que tange a escala do vivido.

Sendo assim, acreditamos que, compreender os processos relacionados ao relevo é essencial, seja num contexto de macro ou microformas. Nesse sentido, indicamos a necessidade de abordar esse conteúdo considerando diferentes escalas. No trabalho docente, essa perspectiva multiescalar valoriza o cotidiano como ponto de partida ou de chegada, e pode favorecer a identificação e compreensão, por parte dos alunos, de processos que ocorrem na sua rua, em seu bairro ou na cidade onde reside, possibilitando-os entender as relações diretas do homem com esse componente do espaço geográfico, as intervenções que realiza neste espaço, bem como as consequências destas para a intensificação ou o desencadeamento de impactos ambientais.

Por fim, reiteramos a importância do SBGFA, especialmente por dedicar um espaço para as pesquisas sobre ensino de Geografia, no qual tem fomentado discussões acerca de diferentes problemáticas que envolvem tanto o contexto da Geografia Acadêmica quanto a Geografia Escolar, o que, por sua vez, tem incitado algumas inquietações, e estas se desdobrado em novas investigações, das quais emergem proposições, contribuindo, assim, para o fortalecimento da ciência geográfica e da sua relevância acadêmica e como disciplina do currículo escolar.

\section{Bibliografia}

XII SIMPÓSIO BRASILEIRO DE GEOGRAFIA FÍSICA APLICADA, 12, 2007. Natureza, Geotecnologia, Ética e Gestão do Território. Anais..., Natal - RN: UFRN, 2007.

XIII SIMPÓSIO BRASILEIRO DE GEOGRAFIA FÍSICA APLICADA, 13, 2009. A Geografia Física Aplicada e as Dinâmicas de Apropriação da Natureza. Anais..., Viçosa - MG: UFV, 2009.

XIV SIMPÓSIO BRASILEIRO DE GEOGRAFIA FÍSICA APLICADA, 14, 2011. Dinâmica Socioambiental, das inter-relações às Interdependências. Anais..., Dourados - MS: UFGD, 2011.

XV SIMPÓSIO BRASILEIRO DE GEOGRAFIA FÍSICA APLICADA, 15, 2013. Uso e ocupação da terra e as mudanças das paisagens. Anais..., Vitória - ES: UFES, 2013.

XVI SIMPÓSIO BRASILEIRO DE GEOGRAFIA FÍSICA APLICADA, 16, 2015. Territórios Brasileiros: Dinâmicas, Potencialidades e Vulnerabilidades. Anais..., Teresina - PI: UFPI, 2015.

BERTOLINI, William Zanete; VALADÃO, Roberto Célio. A abordagem do relevo pela geografia: uma análise a partir dos livros didáticos. Terra e Didática, v. 5, n. 1, p. 27-41, 2009.

MORAIS, Eliana Marta Barbosa de. O ensino das temáticas físico-naturais na Geografia escolar. 2011. $310 \mathrm{f}$. Tese de Doutorado (Doutorado em Geografia), Universidade de São Paulo, São Paulo, 2011.

MORAIS, Eliana Marta Barbosa de. As temáticas físico-naturais como conteúdo de ensino da Geografia escolar. In: CAVALCANTI, Lana de Souza (Org). Temas da Geografia básica. - $1^{\text {a }}$ ed. - Campinas, SP: Papirus, 2013. $217 \mathrm{p}$.

MORAIS, Eliana Marta Barbosa de. As temáticas físico-naturais nos livros didáticos e no ensino de geografia. Revista Brasileira de Educação em Geografia, Campinas, v. 4, n. 8, p. 175-194, 2014. 
ROQUE ASCENÇÃO, Valéria de Oliveira. Os conhecimentos docentes e a abordagem do relevo e suas dinâmicas nos anos finais do ensino fundamental. 2013. 150 f. Tese de Doutorado (Doutorado em Geografia) - Instituto de Geociências, Universidade Federal de Minas Gerais, Belo Horizonte, 2009.

ROQUE ASCENÇÃO, Valéria de Oliveira. A abordagem do conteúdo "relevo" na educação básica. In: CAVAlCANTI, Lana de Souza (Org). Temas da Geografia básica. - 1 ${ }^{\mathrm{a}}$ ed. - Campinas, SP: Papirus, 2013. $217 \mathrm{p}$.

ROQUE ASCENÇÃO, Valéria de Oliveira. O conhecimento do conteúdo relevo: contribuições metodológicas. Geografia Ensino \& Pesquisa, v. 17, n. 1, p. 119-132, 2013.

ROQUE ASCENÇÃO, Valéria de Oliveira; VALADÃO, Roberto Célio. As dimensões escalares e a abordagem de conteúdos geográficos. Anekumene, v. 1, n. 2, p. 152-166, 2011.

SHULMAN, Lee. Conocimiento y enseñanza: fundamentos de lanueva reforma. In: Revista de currículum y formacióndel professorado.nº 09, vol. 02. Universidad de Granada - Esnaã. Ano 9. n. 2, p. 1 - 30, 2005.

SHULMAN, Lee; SHULMAN, Judith H. How and what teachers learn: A shifting perspective. Journal of curriculum studies, v. 36, n. 2, p. 257-271, 2004. 